\title{
Migration and Settlement: A Multiregional Comparative Study
}

An overview of an IIASA book edited by Andrei Rogers and Frans Willekens, and published by the D. Reidel Publishing Company

EXECUTIVE REPORT 9

February 1986 
Executive Reports bring together the findings of research done at IIASA and elsewhere and summarize them for a wide readership. This overview does not necessarily represent the views of the sponsoring organizations or of individual workshop participants. Copies of this Executive Summary can be obtained from the Publications Department, International Institute for Applied Systems Analysis, Schlossplatz 1, A-2361 Laxenburg, Austria.

\section{Copyright (C) 1986}

Sections of this publication may be reproduced in magazines and newspapers with acknowledgment to the International Institute for Applied Systems Analysis. Please send two tear sheets of any printed reference to this report to the Publications Department, IIASA, A-2361 Laxenburg, Austria. 


\section{FOREWORD}

This Executive Report provides a synopsis of the book Migration and Settlement: A Multiregional Comparative Study, the capstone of nearly 10 years of research on multistate demography at the International Institute for Applied Systems Analysis (IIASA). This work, one of IIASA's most successful projects, was led by Professor Andrei Rogers during his tenure at IIASA. Professor Rogers organized teams of researchers in all of the countries in which IIASA had National Member Organizations, East and West, who left a permanent imprint in the form of methods now incorporated in routine national calculations.

Since most of what was accomplished in the course of the Migration and Settlement Study was methodological and descriptive in character, it was natural that future IIASA work in this general area would more intimately involve substance. And this has been the case. During the past year much of substance has appeared, especially in the writings of James Vaupel and Anatoli Yashin. Consequences of heterogeneity in populations, a universal problem of demographic analysis that has been little noticed up to now; social and economic effects of reduced mortality; period and cohort effects in the reduction of mortality; the concentration of reproduction in a surprisingly small fraction of women. Articles announcing the results of this research have appeared or will shortly appear in The American Statistician; Journal of the American Statistical Association; Population Studies; American Journal of Public Health; Population and Development Review.

Nathan Keyfitz IIASA, Laxenburg, Austria 

1

INTRODUCTION

The "population problem" in most parts of the world has two distinct dimensions: growth (positive or negative) and spatial distribution. Concern about population growth has focused attention on fertility patterns and has fostered family planning and family allowance programs in scores of countries. The issue of population distribution, on the other hand, has only recently received serious analytical attention, as programs to encourage the development of economically declining regions, to stem the growth of large urban centers in the less developed countries, and to revitalize the central cores of metropolitan areas have become parts of national agenda all over the globe.

A pressing need for improved methods of measuring migration and understanding its important role in spatial population dynamics led the International Institute for Applied Systems Analysis (IIASA) to organize in 1976 a multinational study of internal migration and population distribution patterns in the countries of its member organizations. Recently developed techniques of multiregional demographic analysis provided the unifying methodological framework for this study, in which scholars from nations of the then 17 Institute member organizations participated. This book is the final product of that effort. 


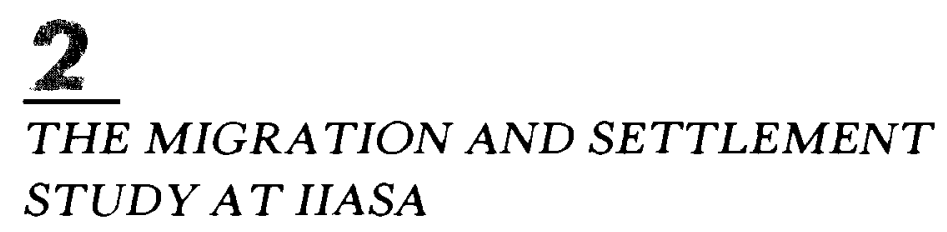

Multiregional demography focuses on the evolution of spatially interdependent regional populations. It considers their sizes, age compositions, and geographical distributions, as well as the changes of these characteristics over time. The principal argument of the multiregional perspective is that it is not enough simply to examine a single regional population when studying its evolution. One must simultaneously also consider the several other regional populations that are interacting with it. The ability of such a perspective to trace the demographic impacts of interregional migration flows and of regionally differentiated regimes of mortality and fertility, make multiregional demography an especially useful tool for projecting subnational populations.

IIASA's study of migration and settlement began with two basic components: a set of computer programs for multiregional demographic analysis and a network of collaborating investigators from nations of the Institute's then 17 member organizations. The principal goal was a case study of each country to be carried out by a scholar from that country. Each study was to use a common methodology and to follow a common outline of substantive topics. Much of the data analysis was to be carried out at IIASA using a standard package of computer programs and most of the scholars involved had to be trained in the methodology by those at IIASA familiar with the mathematical theory. The success of this training led the Institute to offer short courses on multiregional demography in Austria, Mexico, and Bulgaria.

The Migration and Settlement Study was concluded in 1982, seven years after its initiation. An important outcome of the study 
was the set of 17 country reports authored by 27 scholars. Each report presents a national overview of recent regional patterns of fertility, mortality, and internal migration, illustrates the application of multiregional demographic techniques and the additional insights into population redistribution that can be gained from it, and concludes with a very brief review of population distribution issues and policies.

The theoretical work of the Migration and Settlement Study has received wide dissemination. It served as the focus of two sessions on mathematical demography at the annual meetings of the Population Association of America (in 1979 and in 1981). Two special issues of the journal Environment and Planning $A$ were devoted to an exposition of its principal findings (the May 1978 and the May 1980 issues); and a substantial part of a National Science Foundation-sponsored conference on multidimensional mathematical demography focused on its theoretical advances. The study's principal contributions to the theory of multiregional mathematical demography are contained in six research reports which, together with the 17 national case studies, have been issued as a three-volume boxed set, available from the Publications Department of IIASA. The theory, applications, and the data reported therein form the basis of this book. 
THE ORGANIZATION AND CONTENTS

OF THIS BOOK

This volume is the product of a concerted effort by a team of 10 scholars to provide an integrated overview of the principal empirical findings produced in a study carried out by a much larger number of researchers. The empirical foundation of the book is the large data base provided by the national case studies of the Migration and Settlement Study. The underlying methodological perspective of the authors is multiregional demography and the intended outcome is an improved understanding of regional demographic patterns and multiregional population dynamics in the 17 developed countries then represented in IIASA.

\section{PART ONE}

In Part One we introduce the Migration and Settlement Study, preview the book's contents, and consider a number of details related to the study's data base. We consider some of the problems of data collection, account construction, and estimation of missing data brought forth by the national reports. The two accounting frameworks that were implicitly adopted in the 17 case studies are contrasted: movement accounts, which focus on migrations as recurrent events, and transition accounts, which focus on migrants and their places of residence at two different moments in time. The different time and age frameworks used in the IIASA study also come under close scrutiny and the particular problems of incomparability that they give rise to are identified. The regions used in the Migration and Settlement Study are listed and identified on 
maps and methods that were used for dealing with the estimation of missing migration flows are set out.

\section{PART TWO}

The data collected as inputs to the multiregional life table and population projection programs executed at IIASA were assembled primarily to demonstrate the application of a new demographic methodology and not to carry out a comparative study. Consequently, virtually no attention was given to problems of comparability. Nevertheless, the availability of age-specific mortality, fertility, and migration data for 139 regions in 17 countries proved to be seductive and led to an attempt to "compare the incomparable". In Part Two we report on this attempt. In the three chapters we assess the degree of regional variation in mortality, fertility, and migration patterns that prevailed among countries of the IIASA member organizations in the $1970 \mathrm{~s}$.

\section{PART THREE}

Although countries of the IIASA member organizations show considerable variation in national rates of fertility, they nevertheless all tend toward levels of reproduction that are below replacement. By the end of the 1970s, not enough children were being born to replace their parents in 13 of the 17 countries; in the remaining 4 countries (Bulgaria, Czechoslovakia, Poland, and the Soviet Union) the number of children born was only slightly above replacement level. Consequently, in most of the national populations studied the elderly (that is, those 65 years of age and over) increased their share of the total during that decade. Population aging and spatial redistribution in nations of IIASA member organizations are the two principal dimensions illuminated by the Migration and Settlement Study. The three chapters in Part Three of this book address different aspects of these two dimensions.

\section{PART FOUR}

Part Four is devoted to a brief exposition of multiregional mathematical demography and to methodological advances generated by the Migration and Settlement Study in methods of life 
table construction and in stable population theory. Rates, probabilities, and projections are the principal focus of three chapters, whose contents are considerably more mathematical than those of the earlier eight chapters. A short course on multiregional mathematical demography is offered in Chapter 9. In Chapter 10 we focus on the crux of the life table construction problem: the estimation of age-specific survival probability transition matrices using data either on interregional moves or on interregional transitions. In Chapter 11 we set out the analytic solution of a multiregional population projection that is generated by a discrete age-time model with a constant multiregional growth regime. We demonstrate that a stable distribution across ages and regions is implicit in every multiregional population projection matrix. Deviations from these age compositions and regional shares, in the starting age-by-region distribution, ultimately disappear, but in the short-to-medium run they create fluctuations and disturbances in age profiles and in tegional allocations.

Chapter 12 concludes the book. Focusing on the accomplishments of the Migration and Settlement Study, we discuss the three principal themes to which the study's methodological research contributed: spatial population dynamics, measurement and analysis of migration patterns, and formal demographic methods for modeling transitions between states other than regions. 


\section{4 \\ $\overline{C O N C L U S I O N}$}

Regional populations increase because of births and inmigration and decrease through deaths and outmigration. If more people leave an area than come in, there is a negative net migration; the opposite situation gives rise to a positive net migration. The point of the multiregional perspective is that there is no such person as a net migrant. An outmigrant from one region becomes an inmigrant to another, creating a link between two regional populations.

The idea is simple and it is not new. Its immediate consequence for demographic analysis is the need to focus on multiple interacting populations, on flows rather than on net changes in stocks, and on rates that relate the incidence of such flows to the different populations exposed to the risk of experiencing them. Conventional demographic practice follows: from rates to probabilities and from probabilities to well-known life table measures, such as life expectancies, or to well-established procedures for projecting future populations, such as the cohort-survival model.

The perspective of multiregional demography united the efforts of some $\mathbf{4 0}$ scientists, representing over half a dozen disciplines and more than 20 countries, and it focused their attention on contemporary migration and settlement patterns in nations of the then 17 IIASA member organizations. The project lasted seven years and produced a large number of publications. What was accomplished and what was learned?

Most of what was accomplished and learned in the course of the Migration and Settlement Study was methodological and descriptive in character. Because the study's principal aim was to disseminate and expand a methodological tool, this is not 
surprising. The dissemination led to the accumulation of a large data bank, assembled by those adopting the new tool, and this in turn led to a comparative analysis of the data. New problems and ideas arising out of the implementation of the tool in different national settings led to the development of new theoretical findings and methods, most of which contribute to three principal themes: spatial population dynamics, migration measurement and analysis, and multistate demography.

An indicator of the usefulness of a new idea is the degree to which it becomes widely disseminated and applied. Assessed in such terms, the models and computer programs of the Migration and Settlement Study can be said to have attained some measure of success. Expositional articles that deal with applications of multiregional/multistate demography and use IIASA's computer programs continue to appear in different languages in various international scholarly journals. IIASA's methodological work constituted a major focus of a state-of-the-art conference on multistate demography supported by the US National Science Foundation. Governmental agencies, such as the Quebec Bureau of Statistics and the US Bureau of Labor Statistics, have adopted this work, and the new International Encyclopedia of Population refers to it as a fundamental new departure in life table application. Also the IIASA work was adopted by the Netherlands Central Bureau of Statistics and the National Physical Planning Agency of the Netherlands Government.

In a relatively short span of time, the fundamental ideas of multiregional/multistate demography have become widespread and are now receiving attention from scholars in a number of countries. Thus, it is likely that the active period of methodological development of the past decade will continue its evolution. 
THE EDITORS

Andrei Rogers is Director of the Population Program, Institute of Behavioral Science, University of Colorado, Boulder.

Frans Willekens is Deputy Director of the Netherlands Interuniversity Demographic Institute and Professor of Demography at the University of Utrecht. 
Migration and Settlement: A Multiregional Comparative Study, edited by Andrei Rogers and Frans Willekens, has been published by the D. Reidel Publishing Company, in their GeoJournal Library series. Copies of the book (ISBN 90-277-2119-X) are available through your local bookseller, or directly from Kluwer Academic Publishers, 190 Old Derby Street, Hingham, MA 02043, USA (US and Canada) or Kluwer Academic Publishers Group, P.O. Box 322, 3300 AH Dordrecht, Holland (all other countries). 


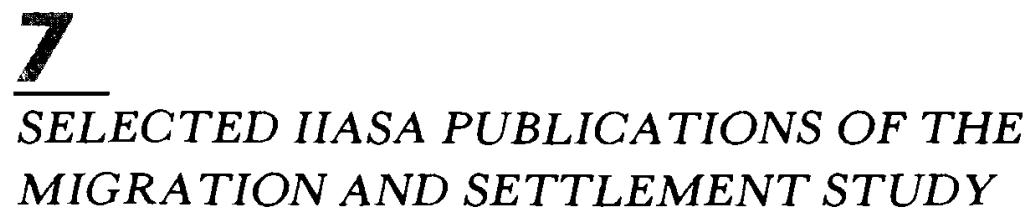

The following publications are available from the IIASA Publications Department, A-2361 Laxenburg, Austria, either individually at the prices shown, or as a three-volume boxed set.

\section{Volume 1: Models, Methods, and Computer Programs}

RR-78-6. Migration and Settlement: Selected Essays. A. Rogers, editor. May 1978. 148 pp. $\$ 10.00$.

RR-78-13. Migration and Settlement: Measurement and Analysis. A. Rogers, F. Willekens. August 1978. 112 pp. $\$ 10.00$.

RR-78-18. Spatial Population Analysis: Methods and Computer Programs. F. Willekens, A. Rogers. December 1978. 302 pp. $\$ 15.00$.

RR-80-10. Essays in Multistate Mathematical Demography. A. Rogers, editor. May 1980. 138 pp. Reprinted from Environment and Planning A; Vol. 12, No. 5. Available for a handling charge of $\$ 3.00$.

RR-81-6. Advances in Multiregional Demography. A. Rogers, editor. May 1981. 203 pp. $\$ 12.50$. 
RR-81-30. Model Migration Schedules. A. Rogers, L.J. Castro. November 1981. 158 pp. $\$ 11.00$

\section{Volumes 2 and 3: National Case Studies}

RR-79-3. Migration and Settlement: 1. United Kingdom. P.H. Rees. September 1979. 167 pp. $\$ 11.00$.

RR-79-9. Migration and Settlement: 2. Finland. K. Rikkinen. November 1979. 119 pp. $\$ 10.00$.

RR-80-5. Migration and Settlement: 3. Sweden. A.E. Andersson, I. Holmberg. March 1980. 117 pp. $\$ 10.00$.

RR-80-6. Migration and Settlement: 4. German Democratic Republic. G. Mohs. March 1980. 122 pp. $\$ 10.00$.

RR-80-13. Migration and Settlement: 5. Netherlands. P. Drewe. May 1980. 87 pp. $\$ 8.50$.

RR-80-29. Migration and Settlement: 6. Canada. M. Termote. August 1980.116 pp. $\$ 10.00$.

RR-80-34. Migration and Settlement: 7. Hungary. K. Bies, K. Tekse. September 1980 . 109 pp. $\$ 10.00$.

RR-80-36. Migration and Settlement: 8. Soviet Union. S. Soboleva. November 1980. 122 pp. $\$ 10.00$.

RR-80-37. Migration and Settlement: 9. Federal Republic of Germany. R. Koch, H.-P. Gatzweiler. November 1980. 78 pp. $\$ 8.50$.

RR-81-16. Migration and Settlement: 10. Austria. M. Sauberer. July 1981 . 119 pp. $\$ 10.00$.

RR-81-20. Migration and Settlement: 11. Poland. K. Dziewoński, P. Korcelli. October 1981. 104 pp. $\$ 10.00$.

RR-81-21. Migration and Settlement: 12. Bulgaria. D. Philipov. October 1981.123 pp. $\$ 10.00$. 
RR-82-5. Migration and Settlement: 13. Japan. Z. Nanjo. T. Kawashima, T. Kuroda. February 1982. 132 pp. $\$ 10.00$.

RR-82-15. Migration and Settlement: 14. United States. L.H. Long, W.H. Frey. April 1982. 132 pp. $\$ 10.00$.

RR-82-28. Migration and Settlement: 15. France. J. Ledent, with D. Courgeau. August 1982. 206 pp. $\$ 12.50$.

RR-82-32. Migration and Settlement: 16. Czechoslovakia. K. Kühnl. September 1982. 133 pp. $\$ 10.00$.

RR-82-33. Migration and Settlement: 17. Italy. D. Campisi, A. La Bella, G. Rabino. September 1982. 104 pp. $\$ 10.00$. 
